\title{
THE LUMINESCENCE OF CERTAIN OXIDES SUBLIMED IN THE ELECTRIC ARC.
}

By E. L. Nichols aNd D. T. Wilber.

\section{SYNOPSIS}

Kathodo Luminescence.-Oxides prepared by sublimation are found to respond to excitation by kathode rays, as well as to flame excitation through a wide range of temperatures.

The Upper Limit of Temperature.-The temperature at which excitation ceases is in general the same, taking each band separately, for flame excitation and for kathodo-excitation.

Color Changes. - The shift in the color of luminescence is in general towards the violet with rising temperature. This shift is produced by the independent growth and decadence of over-lapping bands and not to any lateral movement of the bands themselves.

Influence of Pressure.-Certain bands in the spectra of these oxides are most strongly excited by kathode rays at relatively high pressures, others appear as the vacuum becomes more complete, so that as exhaustion progresses there are marked changes in the color of luminescence.

TN some recent work on luminescence at high temperatures ${ }^{1}$ it became necessary to produce thin films of the substances to be investigated. One method was to place a small quantity of the metal, or of one of its salts, in the crater of a direct-current carbon arc and to collect a layer of the finely divided oxide on a metal strip or disk held in the smoke-laden convection current.

The first films thus obtained were of calcium oxide and these under kathode excitation showed the same fine yellow glow already observed in the study of flame excitation and described in the papers just cited. It seemed desirable therefore to determine what other oxides lent themselves to this method of preparation and to learn something of their luminescent properties.

Of the films prepared in the course of our investigation the oxides of the following metals were notably active.

$\begin{array}{ll}\text { Calcium, } & \text { Zirconium, } \\ \text { Magnesium, } & \text { Silicon, } \\ \text { Zinc, } & \text { Aluminum. }\end{array}$

The luminescence of oxides of lead, boron, barium and strontium was very dim. All other oxides tested, including those of cerium, thorium,

${ }^{1}$ Nichols and Wilber, Proc. Nat. Acad. Dec. 1920; Physical Review (2), I 7, I92 I, p. 453. 
titanium, copper, manganese, bismuth, cadmium and uranium were inactive.

The active films had the following characteristics in common.

I. They are not photo-luminescent at ordinary temperatures.

2. They continue to fluoresce, under kathode bombardment at temperatures far above those at which, in general, photo-luminescence becomes extinct.

3. They are all capable of flame excitation as well as of kathode excitation.

4. In their behavior they are to a great extent independent of the source from which the oxide is obtained: thus calcium oxides produced by the sublimation of the metal, of slaked lime, of calcite crystals or of calcium sulphide appear to be identical as to their luminescence. This is however not a universal characteristic.

5. None of the oxides thus prepared show notable persistent phosphorescence although most of them with small admixtures of chromium, manganese, or bismuth, by suitable heat treatment may, be rendered strikingly phosphorescent. This is particularly true of certain preparations of $\mathrm{Al}_{2} \mathrm{O}_{3}$ with traces of chromium.

6. Like almost all luminescent substances these oxide films are white or very light in color.

7. With rise of temperature changes in the color of the luminescence occur which correspond in general with those observed by Goldstein, ${ }^{1}$ Crookes $^{2}$ and by Wiedemann and Schmidt. ${ }^{3}$

Both Goldstein and Crookes noted the change of the kathodo-luminescence of calcium compounds from yellow towards blue on heating. Wiedemann and Schmidt, in a systematic investigation of the effect, showed that the color shift towards violet was common to numerous substances which they tested up to the temperature where the glass of their vacuum tubes began to soften.

\section{The Upper Temperature Limit of Kathodo-Luminescence.}

To estimate the temperature at which luminescence under the excitation of the kathode-rays ceases, a vacuum tube of the form shown in Fig. I was prepared. By means of the terminals through the ground glass stopper at $C C$ a strip of thin nichrome ribbon $(S)$ could be mounted so as to expose the oxide with which it was coated to bombardment from the kathode $(K)$. The strip was heated by an electric current and its

${ }^{1}$ Goldstein, Wien. Ber., LXXX, p. I5. $_{5}$

${ }^{2}$ Crookes, Proc. Royal Soc., I881, p. 209.

${ }^{3}$ Wiedemann and Schmidt, Wiedemann's Annalen, 56, p. 2 I 8. 
temperature in vacuo was determined in terms of the current. The calibration was made by means of the melting of various selected salts placed in the form of fine powders upon the surface of the strip and these temperatures were checked, above the red heat, by the use of an optical pyrometer (the Morse thermo-gauge).

The extinction of the kathodo-luminescence was quite sharply marked when the nichrome strip with its coating was gradually heated; especially in the case of substances having a greenish or blue fluorescence which was in contrast with the red heat of the background. For calcium oxide, from whatever source sublimed, the temperature of extinction as observed directly with the eye was always the same; i.e., $690^{\circ} \mathrm{C}$.

By observing the glowing strip with the Morse thermo-gauge we could

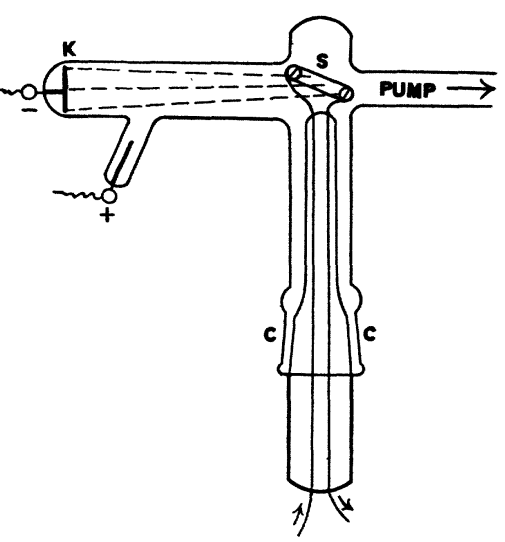

Fig. 1.

measure the equivalent "black body" temperatures of the coating at various actual temperatures of the strip.

It had been established in the course of previous studies ${ }^{1}$ that the spectrum of the luminescent calcium oxide, like that of the calcites from Franklin Furnace, has two broad, complex, overlapping bands. In our pyrometer readings we therefore used a red screen (equivalent wavelength $.65 \mu$ ) and a blue green screen (equivalent wave-length $.48 \mu$ ) and were thus able to study the behavior of the two bands almost independently.

Observations of the color changes showed that the red band began to fall off in brightness at lower temperatures than the green and this was readily confirmed by watching the spectrum as the temperature rose. In spite of the overlapping of the two bands their independent growth and decadence was very striking.

The curves in Fig. 2 indicate roughly, the irregularities being chiefly due to lack of accurate control of the vacuum, the rise of the two curves to a maximum of brightness and their subsidence at the higher temperatures. It will be noted that the red band reaches its maximum at about $280^{\circ}$ at which temperature it has more than double the brightness observed at $20^{\circ} \mathrm{C}$. The green band is not visible at $20^{\circ}$. It attains its maximum at about $425^{\circ}$. Relatively speaking, red is predominant at

${ }^{1}$ H. L. Howes, Physical Review (2), I7, I92 I, p. 460. 
the lower temperatures; green increasingly so from $150^{\circ}$ upwards. The pyrometer is apparently more sensitive than the unaided eye in detecting luminescence superimposed upon temperature radiation.

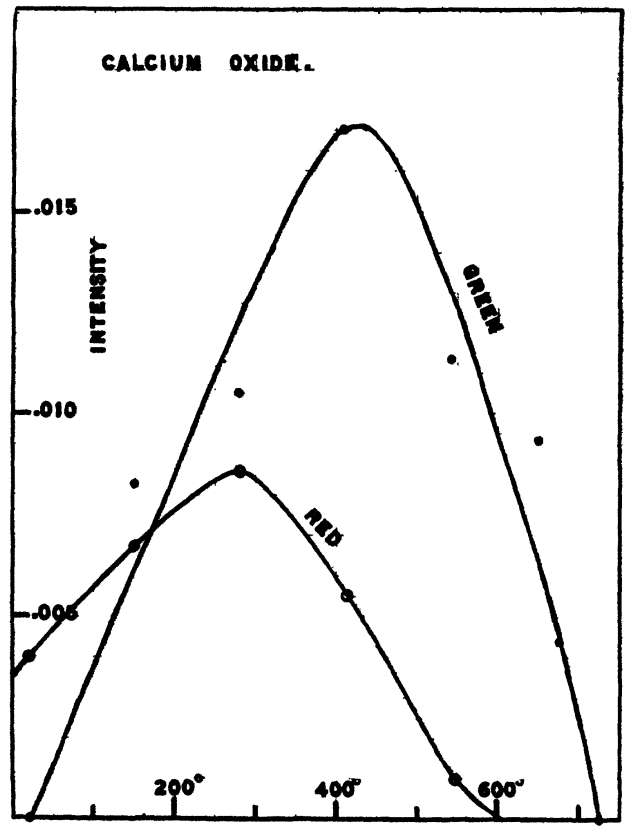

Fig. 2.

TABLE I.

Temperatures and Luminous Intensities of Calcium Oxide.

\begin{tabular}{c|c|c|c|c|c}
\hline \hline \multicolumn{3}{c|}{ Red Screen. } & \multicolumn{3}{|c}{ Green Screen. } \\
\cline { 1 - 2 } $\begin{array}{c}\text { Temp. of } \\
\text { Strip. }\end{array}$ & $\begin{array}{c}\text { Black Body } \\
\text { Temp. }\end{array}$ & $\begin{array}{c}\text { Intensity of } \\
\text { Luminescence. }\end{array}$ & $\begin{array}{c}\text { Temp. of } \\
\text { Strip. }\end{array}$ & $\begin{array}{c}\text { Black Body } \\
\text { Temp. }\end{array}$ & $\begin{array}{c}\text { Intensity of } \\
\text { Luminescence. }\end{array}$ \\
\cline { 6 - 7 } $20^{\circ}$ & $680^{\circ}$ & .0040 & $20^{\circ}$ & - & .0000 \\
$150^{\circ}$ & $702^{\circ}$ & .0067 & $150^{\circ}$ & $712^{\circ}$ & .0083 \\
$280^{\circ}$ & $712^{\circ}$ & .0083 & $280^{\circ}$ & $723^{\circ}$ & .0104 \\
$410^{\circ}$ & $695^{\circ}$ & .0055 & $410^{\circ}$ & $744^{\circ}$ & .0170 \\
$542^{\circ}$ & $644^{\circ}$ & .0010 & $542^{\circ}$ & $726^{\circ}$ & .0113 \\
$650^{\circ}$ & - & - & $650^{\circ}$ & $723^{\circ}$ & .0094 \\
$675^{\circ}$ & $666^{\circ}$ & .0000 & $675^{\circ}$ & $710^{\circ}$ & .0044 \\
$725^{\circ}$ & - & - & $725^{\circ}$ & $690^{\circ}$ & .0000 \\
\hline \hline
\end{tabular}

${ }^{1}$ Note that after the disappearance of luminosity the "black body" temperature is less than the indicated temperature of the strip. This is to be expected in the case of a metallic surface coated with a whitish powder. 
Thus, the disappearance of the green band is found to lie somewhat above $700^{\circ}$ at which temperature it appears to have vanished so far as direct visual observation goes.

\section{Loss of Phosphorescence by Heating.}

One of the striking differences between the behavior of $\mathrm{CaO}$. sublimed in the arc and the calcite from which it is derived, is in the loss of phosphorescence.

Calcite from Franklin Furnace was powdered and sifted upon the surface of the nichrome strip; using powdered rosin as a binder.

When cold this preparation glows in the kathode tube with the well known orange-yellow luminescence, not easily distinguishable from that of $\mathrm{CaO}$ at the same temperature. It has however persistent phosphorescence of long duration. On exciting at higher temperatures, step by step, we find the phosphorescence continuing up to $475^{\circ}$. Above $185^{\circ}$ however the color of the after glow is white instead of red, and even at lower temperatures the red phosphorescence changes to white during decay as had been noted in an earlier paper. ${ }^{1}$

The white phosphorescence grows rapidly dimmer above $325^{\circ}$ but is still persistent being easily observable for several seconds.

Above $475^{\circ}$ persistent phosphorescence was not observable. We made no tests for phosphorescence of the vanishing type.

The fluorescence of this preparation ceased at the usual temperature already established for calcium preparations, i.e., $690^{\circ}$. The substance regained its phosphorescent properties on cooling, so long as it was not heated much above this temperature; but on heating for some 15 minutes at $900^{\circ}$ it underwent a permanent change-probably loss of $\mathrm{CO}_{2}$-and became non-phosphorescent even at room temperatures. It was now indistinguishable from our $\mathrm{CaO}$ prepared in the arc, its luminescence going over from orange to green-yellow on heating and being quenched at $690^{\circ}$.

Another calcite, taken from an old "Crookes tube" and presumably of European origin, developed a fine pale yellow thermo-luminescence when heated. This began to show at $\mathrm{IIO}^{\circ}$, and increased in intensity up to $240^{\circ}$. At this temperature the orange-yellow fluorescence and the very persistent and strong phosphorescence of $20^{\circ}$ were a pale yellow, the phosphorescence dim but persistent. At successively higher temperatures the color of luminescence became paler (i.e., with a movement away from the red). Phosphorescence was very $\operatorname{dim}$ at $355^{\circ}$, scarcely visible at $410^{\circ}$ and gone at $475^{\circ}$. At $475^{\circ}$ the fluorescence was dim, at $542^{\circ}$ very dim and no longer discernible at $615^{\circ}$.

${ }^{1}$ Nichols, Howes and Wilber, Physical Review (2), XII., p. 35 I. 
Heating to $900^{\circ}$ to convert this specimen to $\mathrm{CaO}$ produced a pronounced change in the color of luminescence; the glow when hot being nearly white and when cold of a much paler yellow than before. In this case the power to phosphoresce was not destroyed, there being a rather dim but quite persistent white after glow at the higher temperatures. The ruddy phosphorescence of the calcite however did not reappear.

It seems to be fairly well established that persistent phosphorescence is developed by the presence of considerable proportions of activating materials, as in the phosphorescent sulphides, whereas flame excitation and kathode excitation of fuorescence takes place in the case of pure oxides or of preparations containing minute traces only of activating material. To determine the presence or absence of such infinitesimal admixtures as are known to affect the character of kathode-luminescence is of course well nigh impossible.

\section{The Effect of Pressure.}

In the course of our experiments we noted that the oxide under observation often began to glow under kathode bombardment at relatively very high pressures, reached its maximum at a moderate vacuum and declined almost to extinction at the lowest pressures reached.

That the luminescence at the higher pressures, where the glass of the tube had not begun to glow was of kathodic excitation and not due to ultra-violet radiation was readily determined by the use of a magnet.

By placing in the same tube a coating of $\mathrm{CaO}$, a crystal of calcite and a synthetic ruby it was found that the oxide was in distinct luminescence during the earlier stages of pumping while the ruby and calcite were still dark.

These, however, which began to glow at somewhat lower pressures, soon greatly exceeded the oxide in brightness and continued to increase as the vacuum improved whereas the oxide reached a maximum of intensity and fell off to relative inactivity. Similar effects were observed with $\mathrm{ZrO}_{2}, \mathrm{SiO}_{2}$ and $\mathrm{Al}_{2} \mathrm{O}_{3}$.

To make these observations more definite without going into troublesome refinements a spark gap with nickel-plated balls $25 \mathrm{~mm}$. in diameter was mounted in parallel with the terminals of the tube and observations of the brightness of luminescence of the coating were made with the Morse thermo-gauge, for various sparking distances.

The discharge through the tube during these measurements was obtained from a large four-plate Toepler-Holtz machine.

Any considerable accuracy was difficult owing to the prevailing atmospheric conditions, to unstable states of vacuum within the tube 
and the rather rapid decline in the activity of the coatings which were modified and destroyed by the kathode rays. It was found possible, however, to establish in a semi-quantitative manner the relations between tube voltages and luminescence for films of $\mathrm{CaO}, \mathrm{ZrO}_{2}$ and $\mathrm{SiO}_{2}$. By way of check similar measurements were made upon the kathodo luminescence of a synthetic ruby.

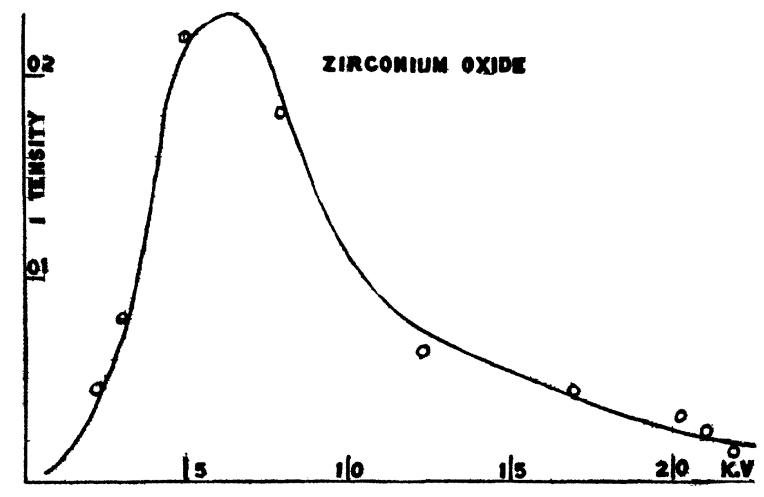

Fig. 3.

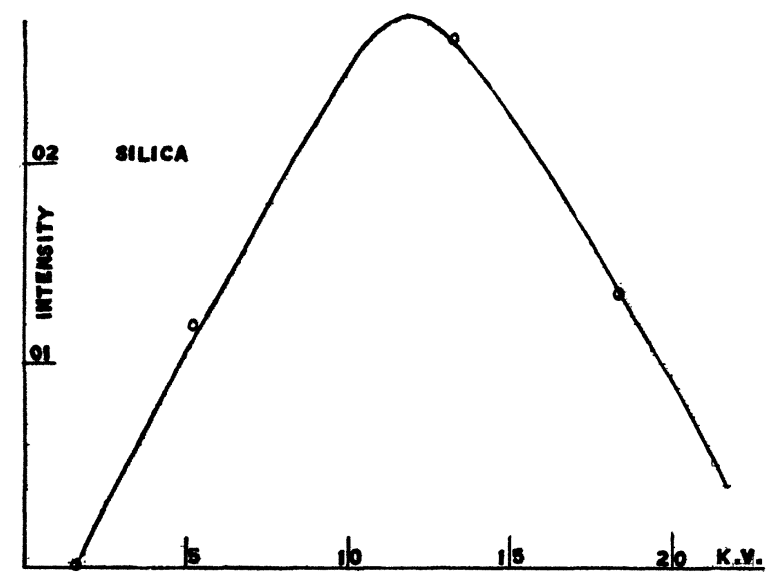

Fig. 4.

The indications of the spark gap were converted into kilovolts by means of curve plotted from measurements by Peek $^{1}$ of the relation between spark gap and voltage. The applicability of his data to the conditions of our experiment was verified by the use of a Braun electroscope.

${ }^{1}$ Peek, Dielectric Phenomena, p. 87. 
The results of our observations are given in Table II., and Figs. 3, 4 and 5 and, for the ruby, in Table III and Fig. 6.

It appears from these curves (Figs. 3, 4 and 5) that there is a wellmarked maximum for each coating beyond which the brightness falls off-

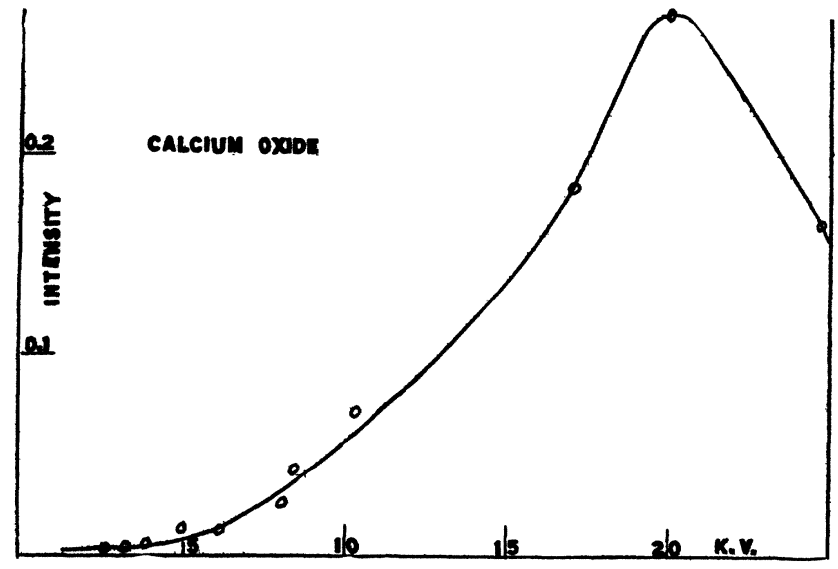

Fig. 5.

a fact which agrees with the visual observations already mentioned. This maximum occurs at the vacuum corresponding to $6 \mathrm{kv}$. for $\mathrm{ZrO}_{2}$, $11.5 \mathrm{kv}$. for $\mathrm{SiO}_{2}$ and $20 \mathrm{kv}$. for $\mathrm{CaO}$. Rejuvenation of the glow could

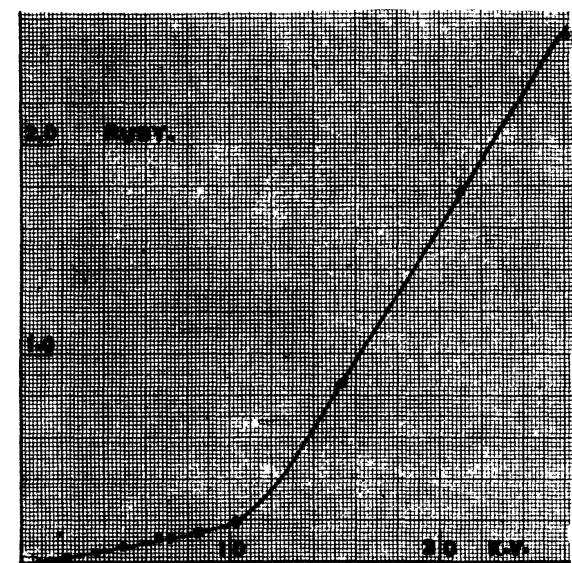

Fig. 6.

be produced at will by pumping until the maximum of brightness was passed and then admitting a small amount of gas to the tube. This brightening up was especially striking in the case of coatings of silicon dioxide. 
TABLE II.

Kathodo-luminescence of Three Oxides at Various Tube Voltages.

\begin{tabular}{|c|c|c|c|}
\hline Substance. & Kilovolts. & B. B. Temp. & Intensity. \\
\hline Calcium oxide.... & $\begin{array}{r}0.8 \\
2.1 \\
2.6 \\
3.1 \\
5.0 \\
6.6 \\
8.5 \\
8.9 \\
10.4 \\
17.3 \\
20.2 \\
24.9 \\
26.2\end{array}$ & $\begin{array}{l}620^{\circ} \mathrm{C} . \\
666^{\circ} \\
670^{\circ} \\
726^{\circ} \\
735^{\circ} \\
728^{\circ} \\
764^{\circ} \\
794^{\circ} \\
819^{\circ} \\
872^{\circ} \\
894^{\circ} \\
874^{\circ} \\
861^{\circ}\end{array}$ & $\begin{array}{l}.0009 \\
.0026 \\
.0029 \\
.0112 \\
.0142 \\
.0120 \\
.0257 \\
.0430 \\
.0750 \\
.1860 \\
.2650 \\
.1680 \\
.1580\end{array}$ \\
\hline Zirconium oxide $\ldots \ldots \ldots \ldots \ldots \ldots$ & $\begin{array}{r}2.4 \\
3.0 \\
5.1 \\
8.0 \\
12.3 \\
17.7 \\
20.3 \\
20.9 \\
21.8\end{array}$ & $\begin{array}{l}686^{\circ} \\
710^{\circ} \\
756^{\circ} \\
750^{\circ} \\
700^{\circ} \\
683^{\circ} \\
675^{\circ} \\
654^{\circ} \\
639^{\circ}\end{array}$ & $\begin{array}{l}.0046 \\
.0080 \\
.0220 \\
.0182 \\
.0061 \\
.0043 \\
.0034 \\
.0025 \\
.0015\end{array}$ \\
\hline Silicon oxide $\ldots \ldots \ldots \ldots \ldots \ldots \ldots$ & $\begin{array}{r}1.4 \\
5.2 \\
13.5 \\
18.4\end{array}$ & $\begin{array}{r}- \\
728^{\circ} \\
765^{\circ} \\
733^{\circ}\end{array}$ & $\begin{array}{l}.0000 \\
.0120 \\
.0262 \\
.0135\end{array}$ \\
\hline
\end{tabular}

TABLE III.

Kathodo-luminescence of the Ruby at Various Tube-Voltages.

\begin{tabular}{c|c|c}
\hline Kilovolts. & Black Body Temp. & Intensity. \\
\hline 0.8 & - & 0. \\
1.7 & $700^{\circ}$ & .0061 \\
2.3 & $776^{\circ}$ & .032 \\
3.6 & $792^{\circ}$ & .045 \\
5.0 & $834^{\circ}$ & .097 \\
6.6 & $850^{\circ}$ & .133 \\
8.5 & $865^{\circ}(?)$ & .140 \\
10.3 & $944^{\circ}$ & .192 \\
15.4 & $1000^{\circ}$ & .841 \\
21.0 & - & 1.75 \\
26.2 & - & 2.45 \\
\hline
\end{tabular}


That the bombardment by the kathode particles did not reach a maximum at the highest of the vacua attained in our experiments is clearly indicated in the curve for the synthetic ruby (Fig. 6). The intensity of luminescence of this crystal increased in direct proportion to the tube-voltage above ro kv., at which point the kathode stream appears to have reached its maximum and constant value.

In view of the fact that these oxides are also capable of flame excitation, one of the most obvious explanations of their luminescence in the vacuum tube would be that the bombardment dislodges portions of the oxide and that it is either the return of these displaced particles that produces fluorescence, or that the material thus partly reduced combines with luminescent effect with free oxygen from the tube. As against the second supposition we found that the rejuvenation of the glow occurred about equally well whether air, pure oxygen or hydrogen was introduced, or whether the pressure change was produced by heating the nichrome strip and driving off its occluded gases or finally by reducing the pressure by the use of liquid air, instead of pumping, and increasing it by the release of the frozen vapors. In this last case especially there would seem to be no change in the free oxygen content of the tube but only change of pressure.

The inference would be that the fluorescence is produced by recombination with oxygen slightly displaced rather than with free oxygen.

That the effect is not due to heating by the kathode particles was very clearly brought out when the heating strip was coated with calcium oxide. The passage of an electric current through the strip enabled us to change the color of the glow of this coating from a ruddy yellow to green before a visible red heat was attained. Kathode bombardment did not however appreciably change the color of the strip, and since the intensity changes with pressure went on at any temperature of the coating, within the temperature range of its activity, it was certain that we had to do with a pressure change rather than a temperature change. In what way the gas pressure affects the actions and reactions, electronic or chemical, upon which the luminescence of these oxides depends remains thus far merely a matter of surmise. It might be suggested, however, as a matter not as yet actually established, that the more intense kathodic bombardments in the higher vacua, tend to drive the oxygen completely off so that there is less and less of the recombination which produces fluorescence. Hence the diminished intensity at higher vacua.

That this effect is not common to kathodo luminescence in general we know from the work of Veazey and T. B. Brown, ${ }^{1}$ from Lenard's ${ }^{2}$

1 T. B. Brown, Physical Review (2), i I, I918, pp. 39-57.

${ }^{2}$ Lenard, Annalen der Physik I2, I903, pp. 449-490. 
earlier experiments and from our measurements on the ruby, just described. It is indeed doubtless an effect peculiar to these oxide films and perhaps incident to their mode of preparation.

The case of aluminum oxide in this respect is instructive. This oxide as has been known since the extended researches of Crookes, Urbain, LeCoq de Boisbaudran, and others, exhibits a great variety of colors in the vacuum tube; green, red and blue and the combinations of these. It is a question of impurities and of heat treatment-a matter to be discussed in a subsequent paper. The combination of red and blue occurs frequently, giving rose colors and purples.

We find that when such a specimen is subjected to kathodic bombardment the blue appears first, at the higher pressures and is gradually replaced by red as the vacuum is improved so that we have successively in the same specimen a high pressure glow (blue) and a high vacuum glow (red).

The immediate, tentative explanation, as above, is that the oxygen is more or less loosely attached as the result of different previous heat treatments, etc., so that the pressure relations of the two bands of the fluorescence spectrum are altogether different.

Physical Laboratory,

CORNELl UNIVERSiTy,

February, I921. 


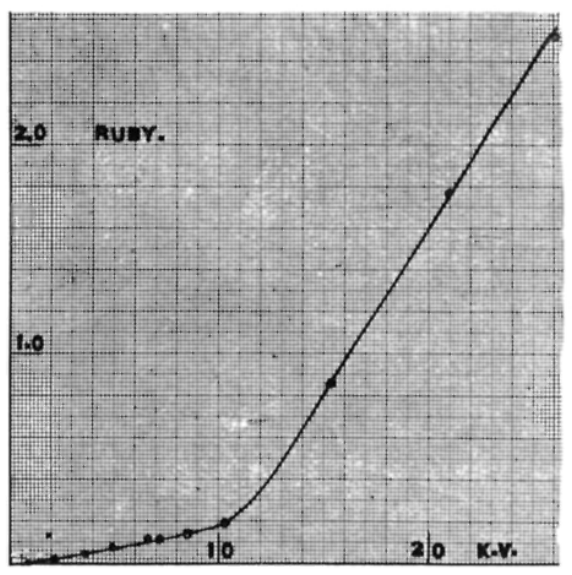

Fig. 6. 